\title{
INTERNET OF ROBOTIC THINGS - AN OVERVIEW OF INTERNET OF THINGS WITH ROBOTIC CLEANERS
}

\author{
Polycarp Yakoi \\ MSc, Computer Engineering Department \\ Cyprus International University \\ Haspolat, Lefkosa, North Cyprus
}

\author{
Hamagham Peter Ishaku \\ $\mathrm{PhD}$ Candidate, Electrical \& Electronics Engineering \\ Cyprus International University \\ Haspolat, Lefkosa, North Cyprus
}

With the growing trend of the need for Internet of Things (IoT) and its applications in different aspects of life, this paper will make familiar the use of IoT more domestically in homes, offices, organizations, etc. to ensure that these places are kept clean at all times. Internet of Robotic Things (IoRT) which is a subset of IoT will be made with robotic cleaners which will be instructed to clean different rooms/places from their stations directly from a server room.

Another thing that will be exposed in this paper is the use of these robots externally as service providers for people. This involves the concept of Service Robots which is expected to dominate the IoRT industry in the coming years. Finally, the methods of powering the robot are discussed.

Keywords - IoT (Internet of Things), IoRT (Internet of robotic Things), robotic cleaners, GPS (Geo Position System).

\section{INTRODUCTION}

As seen in [1], an autonomous navigation robot was created. The robot was created to be a cleaner robot - a robotic vacuum cleaner. The vacuum cleaner has the following features: autonomous, detect and suck dust, detect and dodge obstacles and also an additional feature which is to track its location.

This paper aims to discuss a great deal of how these robots can be made to support IoT. The IoT features coupled with autonomy these robots can be sent to clean rooms in a house, within an organization, firm and other places. Also, can be sent to another place completely outside to clean the required place effectively and efficiently. In other words, this paper will propose a system which will use IoT and cleaner robots to provide cleaning services for anybody at any place. The motivation behind this project is a true attestation of the prediction in [2] that service robots will become a major force in the robotics industry.

\section{LITERATURE REVIEW}

The basic definition of IoRT is the use of IoT features to link robots together to provide (a) service(s). IoT has evolved a lot over the years and as it is growing, so also has it influenced the robotics field immensely too. Robot as a Service (RaaS) is a combination of IoT and robotics where robots provide services in different forms to humans such as serving in a restaurant; this impressive combination of IoT and robotics is gaining waves and is expected to be the future of robotics and IoT [2][6].

This paper discusses a network of robotic cleaners which provides cleaning services for the owner and anyone who wants to rent them. The most important thing is 'the internet', these robots must be connected to the internet [7]. The internet is so important because it will provide a communication link between the robots, the server, other robots and other external things that could benefit the system. Within buildings, Wi-Fi could be used while a mobile data could be used when the robots are not in a reasonable distance from $\mathrm{Wi}-\mathrm{Fi}$, also to ensure that internet is always available the robots will be made to smartly choose the best internet around.

There are applications of IoT and robotics together in many fields. Some of these applications are discussed below:

- Industrial domain: IoT can be used for industrial activities in companies and firms for production, commercial activities, transactions and many more [4].

- Smart city domain: this involves the use of IoT to aid sustain the environment and use smart solutions to solve energy problems [4]. IoT improves communication between humans and their environment, also security can be improved [5].

- Health sector: In the health sector IoT and robots are now used to perform intelligent services that help to improve the lives of people and society at large. Advanced sensors have been developed for thorough monitoring of patients and many more applications exist [4].

There countless examples of IoT and robotics combined and have yielded impressive results. In [12] an intelligent 


\section{International Journal of Engineering Applied Sciences and Technology, 2020 \\ Vol. 5, Issue 5, ISSN No. 2455-2143, Pages 129-132 \\ Published Online September 2020 in IJEAST (http://www.ijeast.com)}

housekeeper was designed; other examples of IoT can be seen in [9] and [10].

Just like other systems that use IoT features, this system when properly built is going to have so many benefits though some of these are already known.

\section{Advantages of robotic cleaners}

Below are the advantages of robotic cleaners generally.

a) Saves time.

b) Detects changes between surfaces.

c) Automatic recharging.

d) Able to go under furniture and around corners.

e) No hurting or soreness of your back.

f) Low noise level.

\section{Disadvantages of robotic cleaners}

The disadvantages or limitations of robotic cleaners are given below.

a) Due to their size, extra-human help is needed to empty the small-sized dustbins always.

b) Battery efficiency can wear down with time even though they recharge automatically.

c) They are usually expensive.

\section{ARCHITECTURE OF THE SYSTEM}

First of all, to ensure that this system will work, it must be ensured that the robots are autonomous. The autonomy of these robots will be partial, this is because, in as much as they will carry out their duties themselves, they will need some directions from an operator in the server room to give instructions such as where to clean in a building, name and address of a renter. An overview of the whole system architecture is shown in Figure 1. The architecture of the whole system has been created using Proteus and Fritzing; both are shown in Figures 3 and 4.

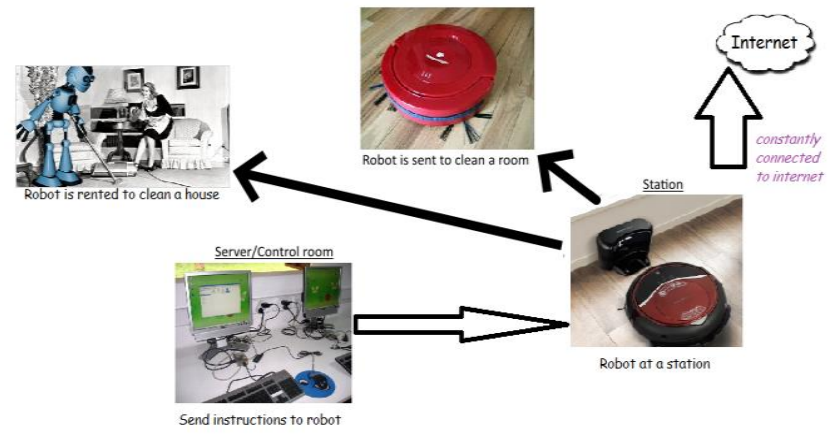

Figure 1: Overview of the system
For the autonomy of the robot, Arduino Uno microcontroller and ultrasonic sensor (HSr04) were used. HSr04 (which is shown in Figure 2) was used to detect obstacles which the robot is expected to dodge.

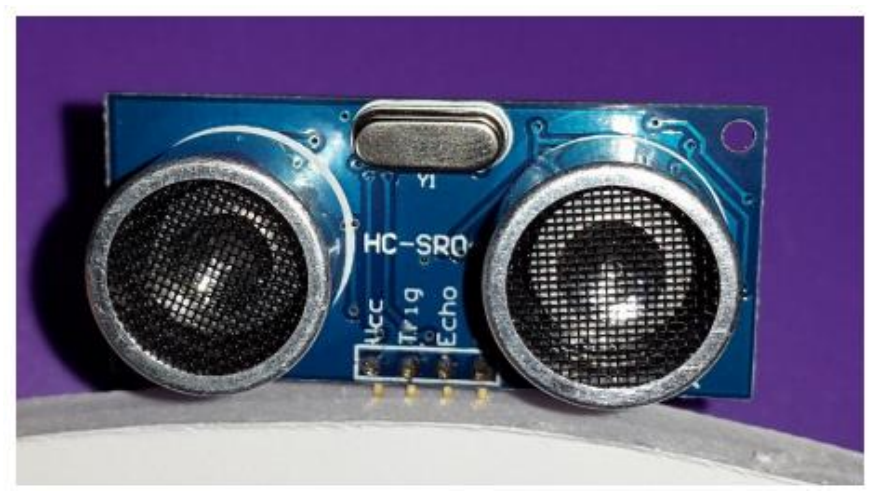

Figure 2: HSr04 (Ultrasonic sensor)

The next component of the system is the navigation parts; these components are wheels, map and GPS. The wheels will be very balanced and strong since the robot is expected to move a lot. The map will be used to tell the robot where to clean inside a building and then together with the GPS to ensure that the robots get to the destination of the renter to clean. Another important thing about the balance of the wheel is that it must be made in such a way that it can climb stairs should there be any need to.

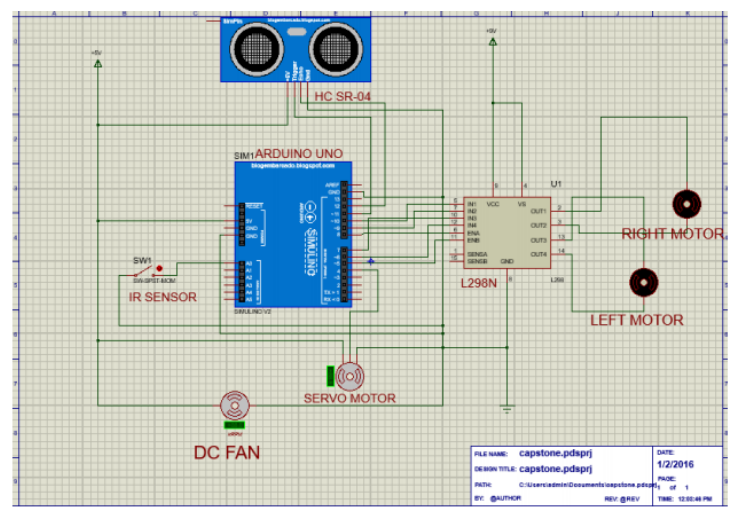

Figure 3: Robot Architecture using Proteus 


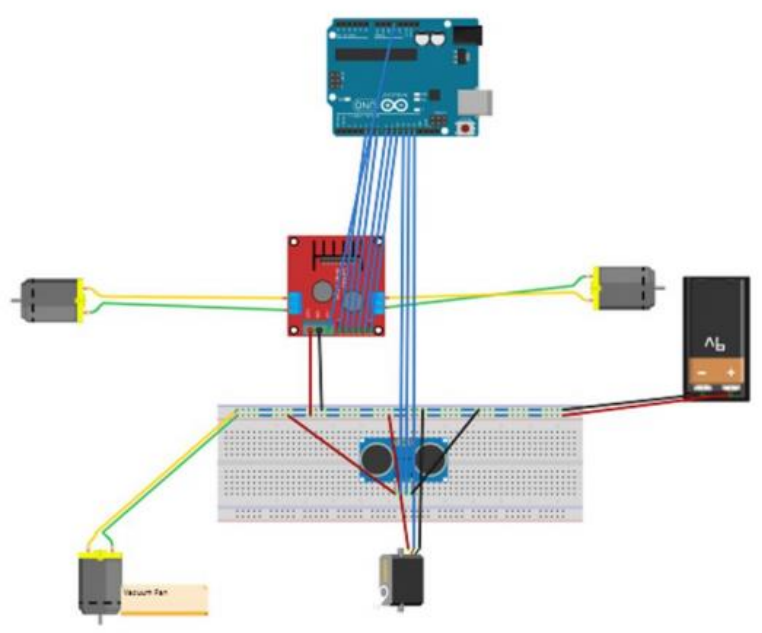

Figure 4: Robot Architecture using Fritzing

The dustbin and the vacuum fan are other important features of these robots. Usually, cleaner robots do have a small dustbin but these will be made to have fairly larger dustbins coupled with powerful vacuum fans to ensure proper cleaning. Also, the robots should be made to be much smarter with the ability to detect external dustbins to empty their dirt when they are full, this will ensure that rooms are cleaned properly and also on time. A sensor could also be added to detect when the dustbin is full to ensure that the dirt does not overflow.

For the internet, as explained earlier, the robots will have the ability to detect Wi-Fi close to them or use a mobile data which will be attached to them and will be used only when there is no Wi-Fi available.

The next component of this system is the energy storage system. This is perhaps one of the most important. To power, these robots, rechargeable batteries of sufficient capacity will be used. An important feature can be added to the robots, they should be smart enough to self-recharge their batteries either through wireless charging or solar PV system, aside from the conventional charging manner which is through a socket connection. How is this possible? The simple answer is that the robot should be able to sense a socket with the wireless charging adaptor and move to closer range to connect to it and when the battery is full it should disconnect itself. For the second option, the robot should have an adjustable solar module connected on it which is directly connected to the battery through a charge controller or voltage regulator. The size and capacity of the rechargeable battery will depend on the size of the robot itself, the kind of work it will perform and the time duration required to perform its duties, and all these will be determined by the manufacturer.

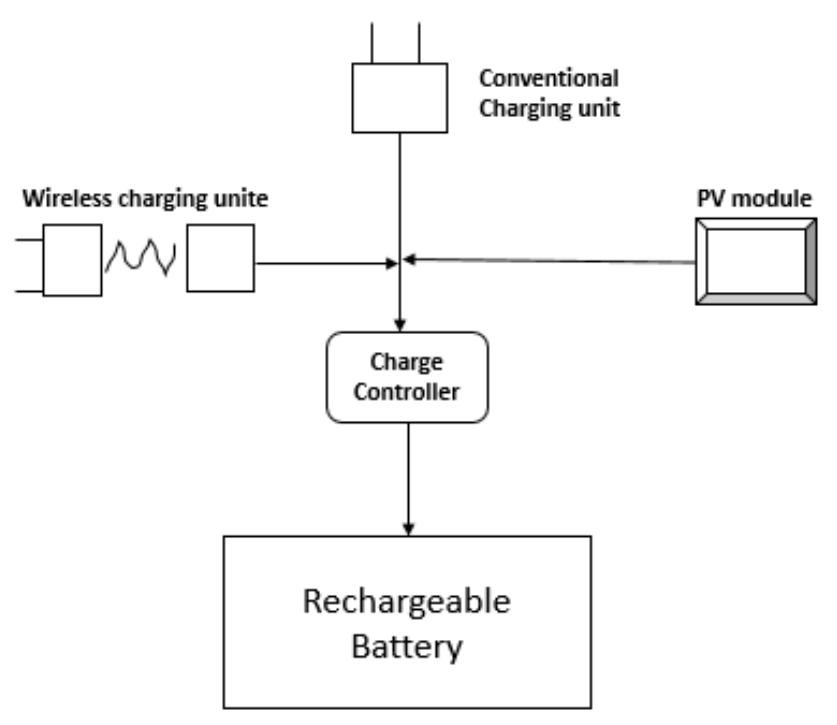

Figure 5: Schematics of the three charging units system

Both the conventional charging unit and the wireless charging adaptor should have and input of $100-24 \mathrm{~V} \mathrm{AC}$ and output with a step-down DC output to the required/operating voltage of the battery. The PV module generates a Direct Current, therefore no need for conversion. The current produced will be sent directly to the battery through the charge controller. Also, the voltage rating of the module will be the same as that of the battery operating voltage. The energy saved in the battery is then sent to the robot system to do work, by powering the control unit and all locomotion units as well as lighten points. The schematics of the charging units of the system is shown in Figure 5.

Another very important feature in the system has to do with the doors in the buildings. The doors can be made to have a particular opening (which will be closed normally) that will allow the robot to enter a room and clean. Logically it is a twoway dynamic, the door has the opening with a mark that the robot can sense and then the robot has a sensor that will detect that mark; also the door (maybe only the opening) should be smart enough to open to allow the robot to enter or exit the room.

\section{CONCLUSION AND FUTURE WORKS}

From all the discussions from the beginning of this paper until now, the benefits and limitations can be comparable to what we have above, only with a little variation. All the benefits above can be enjoyed also by using the system, but there are additional advantages that were not listed above, which is cost-effectiveness and power sustainability. With the option of being able to be rented, people will no longer need to own the robot, but rather they just contact the operators and pay the rental fee. The use of solar PV system provides a selfconsumption method which improves the system sustainability and reduces the cost of power consumption. 


\section{International Journal of Engineering Applied Sciences and Technology, 2020 \\ Vol. 5, Issue 5, ISSN No. 2455-2143, Pages 129-132 \\ Published Online September 2020 in IJEAST (http://www.ijeast.com)}

As seen from the added advantages above, the third disadvantage is solved. To avoid the high cost of buying people can just rent these robots. The first disadvantages also have been solved, how? It has been explained earlier that robots will have a fairly larger dustbin and will also be smart enough to detect close-by external dustbins to empty theirs. Realistically the major limitations to this system are how to take them out into the market and how to navigate properly to the renters' place. This is very important because there are external factors and things such as people and traffic that could cause more problems than anticipated. With proper implementation and the right equipment, these problems can be solved and the system will be very important in the IoRT industry.

This paper has been able to propose a service cleaner robot which will be able to clean rooms within a building which also will be made available for rent by other people. It has been discussed that the robots will be partially autonomous and will use IoT features to communicate with an operator to get instructions. It has also been discussed that the major problem of the robot will be navigation to renters' places which can be solved by using the proper equipment and proper implementations.

\section{REFERENCES}

[1] F. Mbarouk, P. Yakoi \& B. Mels, "Autonomous Navigation Robot- Vacuum Cleaner," BSc. Capstone Project, Dept. Elect. \& Comp. Eng., Cyprus International University, Lefkosa, North Cyprus, 2016.

[2] V. Baya and L. Wood, "Service robots: The next big productivity platform," PwC Technology Forecast: Future of robots Issue 2, 2015

[3] L.A. Grieco, A. Rizzo, S. Colucci, S. Sicari, G. Piro, D. Di Paola, G. Boggia, "IoT-aided robotics applications: Technological implications, target domains and open issues," 2014 Elsevier B.V.

[4] E. Borgia, "The Internet of Things vision: Key features, applications and open issues," 2014 Elsevier B.V.
[5] B. Guo, D. Zhang, Z. Wang, Z. Yu, X. Zhou, "Opportunistic IoT: Exploring the harmonious interaction between human and the internet of thing," 2014 Elsevier B.V.

[6] Y. Chen, H. Hu "Internet of intelligent things and robot as a service," 2012 Elsevier B.V.

[7] V. Dutta, T. Zielinska, "Networking technologies for robotic applications"

[8] A. Al-Fuqaha, M. Guizani, M. Mohammadi, M. Aledhari, M. Ayyash, "Internet of Things: A Survey on Enabling Technologies, Protocols, and Applications," IEEE COMMUNICATION SURVEYS \& TUTORIALS, VOL. 17, NO. 4, FOURTH QUARTER 2015

[9] C. M. Shah, V. B. Sangoi, R. M. Visharia, "Smart Security Solutions based on Internet of Things (IoT)", 2014 INPRESSCO

[10] D. Palma, J. Enrique Agudo, H. Sánchez and M. Macías"An Internet of Things Example: Classrooms Access Control over Near Field Communication," Sensors 2014, 14, 6998-7012; doi:10.3390/s140406998

[11] J. F. C. Arias, Y. J. C. Barajas, J. L. R. Lopez, "Wireless Sensor System According to the Concept of IoT - Internet of Things," International Journal of Advanced Computer Science and Information Technology Volume 3, Issue 3, 2014, ISSN: 2296-1739

[12] S. Wang, H. Zhao and X. Hao, "Design of An Intelligent Housekeeping Robot Based on IOT," ICIIBMS 2015, Track2: Artificial Intelligence, Robotics, and HumanComputer Interaction, Okinawa, Japan 978-1-4799-85623/15/\$31.00 @2015 IEEE

[13] S. Khoshafian, "The Future of Work Automation: the impact of IoT and Robotics," Dec 012015 Pegasystems Inc.

[14] J. V. Berná-Martínez, F. Maciá-Perez, "Robotic control systems based on bioinspired multi-agent systems," 2011, (IJAEST) INTERNATIONAL JOURNAL OF ADVANCED ENGINEERING SCIENCES AND TECHNOLOGIES Vol No. 8, Issue No. 1, 032 - 038 